\title{
Bioremediation of Oil-Based Paint from Aqueous Media by Novel Indigenous Brevibacillus parabrevis Strain NAP3 and its Toxicity Assessment
}

\author{
Anwar Hussain Phulpoto", Muneer Ahmed Qazi, ${ }^{1,2}$, Shahida Mangi ${ }^{1}$, Safia Ahmed ${ }^{2}$, \\ Ihsan-Ul-Haq ${ }^{3}$, Abdul Rahman Phul ${ }^{3}$, Nisar Ahmed Kanhar ${ }^{1 *}$ \\ ${ }^{1}$ Department of Microbiology, Shah Abdul Latif University, \\ 66020 Khairpur, Sindh, Pakistan \\ ${ }^{2}$ Department of Microbiology, Faculty of Biological Sciences, Quaid-i-Azam University, \\ Islamabad, 45320 Pakistan \\ ${ }^{3}$ Department of Pharmacy, Faculty of Biological Sciences, Quaid-i-Azam University, \\ Islamabad, 45320 Pakistan
}

Received: 19 February 2016

Accepted: 26 April 2016

\begin{abstract}
The present study sought to explore the bioremediation of oil-based paint from aqueous media using indigenous bacterial isolate Brevibacillus parabrevis strain NAP3 and its toxicity assessment against prokaryotic and eukaryotic biological models. The bacterial isolate was initially screened for bioremediation potential in mineral salts medium containing oil-based paint (conc. $300 \mathrm{ppm}$, w/v) under shake flask settings. Moreover, the percentage removal of oil-based paint from aqueous media was investigated using a spectrophotometer at $285 \mathrm{~nm}$ under two different experimental conditions, i.e., with and without glucose. Evidently, the bacterial isolate displayed maximum oil-based paint removal of $83 \%$ in flasks containing glucose as an additional carbon source after 14 days of the treatment, whereas without glucose supplementation it reached up to 78\%. The Fourier transform infrared (FTIR) spectra showed noticeable biodegradative changes of the oil-based paint relevant to peaks in the wave number frequency range of $800-600 \mathrm{~cm}^{-1}, 1,034$ to $1,299 \mathrm{~cm}^{-1}, 1,690$ to $1,725 \mathrm{~cm}^{-1}, 2,857$ to $3,000 \mathrm{~cm}^{-1}$, and 3,200 to $3,400 \mathrm{~cm}^{-1}$ (corresponding to $\mathrm{C}-\mathrm{H}, \mathrm{C}-\mathrm{O}-\mathrm{N}, \mathrm{C}-\mathrm{O}-\mathrm{C}$, and $\mathrm{CH}_{2}$ aliphatic stretch and terminal $\mathrm{CH}_{3}$ bonds, and $\mathrm{N}-\mathrm{H}$ bonds, respectively, in treated samples as compared to controls; non-inoculated samples). After treatment, the cellfree supernatants containing oil-based paints displayed reduced cytotoxicity against brine shrimp larvae, phytotoxicity against wild reddish seeds, and antimicrobial activity against selected pathogenic bacteria and fungi, which indicated the possible use of $B$. parabrevis as potential oil-based paint-degrading bacterium in order to restore paint-polluted environments.
\end{abstract}

Keywords: bioremediation, Brevibacillus parabrevis, oil-based paints, cytotoxicity, phytotoxicity, antimicrobial activity

*e-mail: nisar.kanhar@salu.edu.pk 


\section{Introduction}

Oil-based paints are widely used complex industrial toxic materials with high solubility in organic solvents [1]. The worldwide production of industrially applied paints grew from 6.3 million tons in 1980 to 10.5 million tons in 2006. In contrast, for the same period, solvent consumption hardly increased from 4.1 to 4.2 million tons - a consequence of the increasing use of oil and solventreduced paints [2]. The disposal and spillages of such oilbased paints in the environment can result in environmental pollution and poses serious risk to human health [3]. The risks are mainly associated with the inhalation of gaseous vapors from solvents, additives, pigments, and mists generated during the spraying, as well as contact and absorbance through the skin [1]. In 1989, the International Agency for Research on Cancer (IARC) classified painting as an occupation that is carcinogenic to humans [4]. There is sufficient evidence of carcinogenicity in humans for occupational exposure as a painter. Occupational exposure as a painter causes cancer of the lung and of the urinary bladder [4]. Most researchers have focused mainly on oil-based paint toxicity and its hazardous impacts on the environment [1]. Multiple cytogenetic effects among car painters have been previously reported [5], who found that exposed subjects had higher frequencies of chromosomal aberrations than unexposed control subjects.

Although various physical and chemical methods have been used to remove environmental pollutants like oil-based paints [6], such methods are expensive and add toxic and biologically persistent chemicals to the environment. Alternately, biological treatments are more feasible and cost-effective alternatives to chemical and physical methods without adding any toxic and persistent chemicals into the environment [7-11]. In general, most of the biological treatment methods rely on the acclimatization of indigenous microorganisms like bacteria and fungi to the contaminated environment. Several studies have been reported for the use of bacterial strains such as Pseudomanas, Acinetobacter, Burkhoderia cepacia, Bacillus nealsonii [11], Serretia marcescens [12], Streptomyces phaeoviridae [13], Micrococcus, Sphingomonas, Mycobacterium, Clostridium, Alcaligenes, Bacillus, Flavobacterium, Arthrobacter, Staphylococcus, Gracilibacillus, Salibacillus, Virgibacillus, and Shewanella [14-16].

Since the oil-based paints are made up of a wide range of hydrocarbons, media enriched with oil-based paints serve as a rich source of carbon and energy for several microbial species [17]. Although several factors affect bacterial numbers and activities in soil, including soil type and season [17], only a few studies in the literature have addressed the removal of oil-based paints and/or paintrelated waste materials from paint-polluted environments [1]. In the present study, an indigenous oil-based paint utilizing the bacterial strain of B. parabrevis was isolated and characterized from oil-based paint polluted soil samples and assessed for the biodegradation of oil-based paints in aqueous media using a shake flask experiment.
The biodegradation efficiency was subjected to toxicity removal and was thus confirmed by cytotoxicity, phytotoxicity, and antimicrobial assays before and after treatment.

\section{Materials and Methods}

The present study was carried out at the postgraduate research laboratory (PGRL) of the Department of Microbiology, Shah Abdul Latif University, Khairpur, and partly at the Microbiology and Pharmacy departments of Quaid-i-Azam University, Islamabad, Pakistan. All the experiments were performed in triplicate unless mentioned otherwise. The data shown in the tables and graphs designate arithmetic mean \pm standard deviation of the triplicate experiments.

\section{Chemicals, Media, and Reagents}

The oil-based paint white-32 (ALBA synthetic enamel, Lahore) was purchased from the local market of Khairpur, Pakistan, and used in the present study as a sole source of carbon and energy. The oil-based paint was dissolved in petroleum ether (Sigma-Aldrich, Germany). The inorganic salts used in Mineral salts media were purchased from Merck KGaA(Germany). All the commercial culture media like nutrient agar were purchased from Oxoid (UK). Brine shrimp (Artemia salina) eggs used in cytotoxicity analysis were purchased from Sera (Heidelberg, Germany).

\section{Collection of Soil Sample and their Treatment}

Paint-polluted soil samples were collected from the warehouses of Khairpur (Lat: $27^{\circ} 31^{\prime} 34.442 " N$; Lon: 68 45'31.789"E) and Sukkur (Lat: 2741'38.897"N; Lon: 68 52'7.258"E), Pakistan. Adapting Wieser, et al., [18] aerobic surface sediment samples were scraped off to a depth of 3 to $10 \mathrm{~mm}$ from extensively dried areas showing extensive damage, with visible and invisible discoloration. The collected samples were transferred to the laboratory and stored at $4^{\circ} \mathrm{C}$ until inoculation. A soil sample (1g) was added to a conical flask containing $50 \mathrm{ml}$ distilled water, homogenized $\left(200 \mathrm{rpm}, 37^{\circ} \mathrm{C}, 30 \mathrm{~min}\right.$.), and left undisturbed for $30 \mathrm{~min}$. under static conditions to allow the soil debris to settle [19].

\section{Enrichment of Oil-Based Paint-Degrading Bacteria}

In order to enrich oil-based paint-degrading bacteria, a predetermined amount $(3 \%)$ of oil-based paint stock solution was added to a $250 \mathrm{ml}$ conical flask to obtain the final concentration of $(300 \mathrm{ppm} / \mathrm{ml})$ and the flask was filled with $100 \mathrm{ml}$ sterilized mineral salt medium (MSM) of determined composition prepared with slight modification from Yonetani, et al. [20], and adjusted to $\mathrm{pH} 7.0 \pm 2$ using $6 \mathrm{~N} \mathrm{HCl}$ and $1 \mathrm{M} \mathrm{NaOH}$ solutions. The sterile MSM contained ( $\mathrm{g} \mathrm{l}^{-1}$ of distilled water): $\mathrm{MgSO}_{4}, 7 \mathrm{H}_{2} \mathrm{O}, 10 ; \mathrm{CaCl}_{2}$, 
$7 \mathrm{H}_{2} \mathrm{O}, 0.2 ; \mathrm{KH}_{2} \mathrm{PO}_{4}, 13.6 ;\left(\mathrm{NH}_{4}\right)_{2}, \mathrm{SO}_{4}, 2.4 ; \mathrm{FeSO}_{4}, 7 \mathrm{H}_{2} \mathrm{O}$, 0.2 ; and $\mathrm{Na}_{2} \mathrm{HPO}_{4} \cdot 12 \mathrm{H}_{2} \mathrm{O}, 15$; whereas the agar $\left(12 \mathrm{gl}^{-1}\right)$ was added into the medium for MSM agar only. Subsequently, the fresh processed sample $(0.1 \mathrm{ml})$ was inoculated into the conical flasks. Flasks were incubated at $37^{\circ} \mathrm{C}$ in a multitier environmental shaker (Innova, Germany) at $160 \mathrm{rpm}$ for 14 days. The oil-based paint utilization in the enriched medium was determined by increasing the turbidity and increasing bacterial biomass by using a spectrophotometer (Jennway 6300, Germany) at $600 \mathrm{~nm}$ with a one-day gap. Samples showing maximum absorbance were selected for isolation and were streaked on the surface of fresh MSM agar medium plates.

\section{Isolation and Identification of Bacterial Isolate}

The streaked MSM agar (MSM containing agar, 1.2\% $\mathrm{w} / \mathrm{v})$ plates were incubated at $37^{\circ} \mathrm{C}$ for the isolation of $B$. parabrevis. The bacterial colonies were picked off from the MSM agar plates and purified by repetitive streak method on the surface of nutrient agar plates. Pure bacterial isolate was then identified by microscopic and biochemical tests, i.e., gram staining and catalase/fermentation tests, etc. Furthermore, the molecular identification of the strain was commercially carried out by partial sequencing of the $16 \mathrm{~S}$ rRNA gene at the Genomic Division, Macrogen Inc., Seoul, Korea. The isolate was identified using a set of universal primers 27 F (5- AGAGTTTGATCCTGGCTCAG-3) and 1492R (5-TACGGYTACCTTGTTACGACTT-3). The amplified gene products were then purified and sequences were obtained through ABI PRISM Big Dye Terminator Cycle Sequencing Ready Reaction Kit (PE Biosystem, USA) using universal sequencing primers, i.e., 518F (5'-CCAGCAGCCGCGGTAATACG-3') and 800R (5'-TACCAGGGTATCTAATCC-3'). The partial amplified sequence obtained was analyzed and compared with a nucleotide sequence database in the National Centre for Biotechnology and Information (NCBI) using Basic Local Alignment Search Tools (BLAST) to confirm percentage sequence similarity. The evolutionary history was inferred using the maximum likelihood method based on the Tamura-Nei model [21]. Evolutionary analyses were conducted in MEGA6 according to [22-23]. The nucleotide sequences of the isolate were submitted to GenBank NCBI for the accession numbers.

\section{Culture Conditions for Bioremediation of the Oil-Based Paint}

The single colony of B. parabrevis was inoculated into nutrient broth for 24 hours in an environmental shaker at $160 \mathrm{rpm}$ and $37^{\circ} \mathrm{C}$. The overnight inoculated broth tubes were centrifuged at 4,000 rpm for 10 minutes and cells were collected. The collected cells were washed thrice in normal saline $(0.9 \% \mathrm{NaCl} \mathrm{w} / \mathrm{v})$ and centrifuged to remove excessive media components. Finally, the collected cell pellet was added to MSM broth to serve as inoculum for biodegradation. Oil-based paint removal was determined in a $250 \mathrm{ml}$ Erlenmeyer flask containing $100 \mathrm{ml}$ MSM broth with and without glucose $(5 \mathrm{mM})$, at the oil-based paint (final conc. 300 ppm) for 14 days of incubation. Erlenmeyer flasks were incubated at $37^{\circ} \mathrm{C}$ in an environmental shaker (160 rpm) for 14 days. Samples were taken at regular one-day intervals and tested for oilbased paint removal. Non-inoculated medium served as negative control. Absorbance was taken for all the test samples and negative controls. The absorbance values of the negative controls were subtracted, and then removal of oil-based paint from each sample was estimated.

\section{Analytical Methods}

\section{Bioremediation of Oil-Based Paint}

The oil-based paint was dissolved in petroleum ether at standard oil-based paint (conc. 100 ppm, 200 ppm, and $300 \mathrm{ppm}$ ), and absorbance was taken using a VUVis spectrophotometer (Agilent-8453, USA) at $\lambda \max$ $(285 \mathrm{~nm})$ against a blank of petroleum ether. The equation for quantification (eq. 1) was drawn by plotting the known concentrations of oil-based paint versus absorbance (Fig. 2). Subsequently, the percentage of oil paint removal for the indigenous bacterial isolate $B$. parabrevis (NAP3) was determined using the linear regression curve:

$$
y=0.0089 x-0.016
$$

...where " $y$ " designates the absorbance at specified wavelength and " $x$ " denotes concentration of the oil-based paint in the aqueous medium.

\section{Fourier Transform Infra-Red-Attenuated Total Reflectance (FTIR-ATR) Spectrometry}

The fourier transform infra-red (FTIR) spectra of the oil-based paint control (300 ppm) and cell-free culture supernatant were recorded using a bench-top TENSOR 27 FTIR spectroscope (Bruker, Germany) equipped with universal PIKE-MIRacle Single Reflectance ATR accessory (PIKE Technology, Germany). The cellfree culture supernatants (CFCS) of the biodegradation experiments were obtained at days 0 and 14 of incubation and interpreted for changes after treatment in the percent transmittance of specific peaks related to that of oil-based paint before treatment. The $100 \mu \mathrm{l}$ of the CFCS was placed on the probe and FTIR-ATR spectra were recorded in the range of wave number 4,000-600 $\mathrm{cm}^{-1}$ with a speed of 16 scans per spectrum at room temperature (approx. $35^{\circ} \mathrm{C}$ ).

\section{Toxicity Assessment}

\section{Cytotoxic Effect}

The cytotoxic effect of oil-based paint was determined against eukaryotic brine shrimp larvae (Artemia salina) 
according to Jamil et al. [24]. Briefly, 20 phototropic nauplii (the hatched brine shrimp larvae) were collected using a Pasteur pipette and transferred to the microtiter 96 well plate containing sea saltwater and yeast extract (50 $\mu \mathrm{l})$ per well of the plate. Afterward, the volume in each well was raised up to $500 \mu 1$ with sample (CFCS), while in negative control the volume was raised with distilled water instead of the sample. The 96 well plate was then incubated under light at $30^{\circ} \mathrm{C}$. Subsequently, the number of live and dead shrimps was counted with the aid of a magnifying glass in the stem of the Pasteur pipette after 24 and $48 \mathrm{~h}$. The lethal dose $\left(\mathrm{LD}_{50}\right)$ was then determined by statistical software TableCurve (version 12.4).

\section{Phytotoxic Effect}

The phytotoxic effect of CFCS $(500 \mu \mathrm{l})$ containing oilbased paint at final concentration $300 \mathrm{ppm}$ of B. parabrevis (NAP3) was observed on the seed germination and seedling growth of wild radish seeds as reported previously [25-26]. The seeds were surface sterilized by rinsing with $0.1 \%$ mercuric chloride for $4-5$ minutes and again washed twice with the sterile distilled water and allowed to dry on Whatman filter paper No.1. Circle-shaped autoclaved filter paper was placed inside a Petri plate and $500 \mu \mathrm{l}$ of each sample (CFCS) was added into a single plate to wet the filter paper. Seeds $(n=20)$ were placed in a single plate on a wetted filter paper and incubated at $25^{\circ} \mathrm{C}$ under a light bench. The total number of seeds germinated was counted on the third day of incubation. Mean value of root length and shoot length was determined on day 5 of incubation, when the emergent radical reached $2 \mathrm{~mm}$ length. Distilled water and 2,4-dichloroacetic acid was used as control. The experiment was performed in triplicate to get promising results.

Different parameters were then calculated as follows:

Final germination percentage $(F G \%)=F G$ is the maximum average percentage of seeds that germinated during the experiment:

- Rate of germination $R G=\Sigma N_{i} D_{i}$

- Mean period of final germination

$(\mathrm{MPFG})=\Sigma N D / F G$

- Percentage inhibition $=1-[F G$ in $C F C s(\%)$

$/ F G$ in control $(\%)] \times 100$

...where $\mathrm{N}$ is the daily increase in seedling number and $\mathrm{D}$ is the number of days from seed placement. The effects on seedling growth, root length (RL in $\mathrm{cm}$ ), and shoot length (SL in $\mathrm{cm}$ ) were measured at day 5. RL and SL were calculated from seed base to root tip and shoot tip (the longest leaf), respectively, using a ruler $(+0.1 \mathrm{~cm})$.

Percentage inhibition in seedling growth for each tested plant was calculated as:

Percentage inhibition in seedling growth

$$
=[(N-S / N)] \times 100
$$

\section{Antibacterial Effect}

Antibacterial activity was determined using the agar well diffusion method as described by Jamil et al. [24].
The CFCS of B. parabrevis before and after treatment of 14 days was used against bacterial strains (Micrococcus luteus ATCC 10240, Salmonella typhi ATCC 14028, and Pseudomonas aeruginosa ATCC 9027). Briefly, $0.75 \mathrm{ml}$ of the broth culture containing $10^{8}$ colony forming units (CFU) per $\mathrm{ml}$ of the test strains were added to $75 \mathrm{ml}$ of nutrient agar medium at $45^{\circ} \mathrm{C}$, mixed well, and then poured into $14 \mathrm{~cm}$ sterile petri plates. The medium was allowed to solidify and 8-mm wells were dug with a sterile metallic borer. $100 \mu \mathrm{l}$ of the CFCS and $200 \mu \mathrm{g} / \mathrm{well}$ of Cefotaxime as control were added to each petri plate and incubated $\left(37^{\circ} \mathrm{C}, 24 \mathrm{~h}\right)$. After incubation, the diameter of the clear zones showing no bacterial growth around each well were measured.

\section{Antifungal Effect}

The CFCS of B. parabrevis was evaluated for antifungal effect to compare the toxicity of oil-based paint before and after treatment. The assay was performed by agar well diffusion method as described by Jamil et al. [24] with slight modification. Clotrimazole was used as standard drug (positive control) and DMSO was used as negative control. Briefly, an aliquot $(100 \mu \mathrm{l})$ of CFCS was used for the antifungal activity before and after treatment against fungal strains (Aspergillus niger FCBP 0198, Aspergillus fumigatus FCBP 0066, and Aspergillus flavus FCBP 0064) on Sabouraud dextrose agar (SDA). All apparatus required in the assay were autoclaved for sterilization. For the assay, SDA media petri plates were streaked with fungal spores followed by $8-\mathrm{mm}$ wells made with a sterile metallic borer, and each Petri plate was added with CFCS $(100 \mu \mathrm{l})$ and Clotrimazole $(200 \mu \mathrm{g}$ per well) as control. Thereafter, the plates were incubated $\left(24 \mathrm{~h}, 28^{\circ} \mathrm{C}\right)$ and zones of inhibition were measured by using a vernier caliper.

\section{Results and Discussion}

\section{Sample Collection and Isolation}

Different environmental scientists have collected the waste samples for isolation of microbial community having desired activities of degrading environmental pollutants [27-28]. Therefore, in the present study seven oil-based paint-polluted soil samples were collected from paint warehouses of Khairpur and Sukkur, Pakistan, for the isolation of oil-based paint-degrading bacteria. Oilbased paint (ALBA synthetic enamel white-32) was used (300 ppm) as the sole source of carbon and energy in MSM broth for the isolation of oil-based paint-degrading strains using a shake flask experiment. Obtaining bacteria with a desired metabolic capability directly from natural habitats is rarely feasible [29]. To isolate bacteria of desired metabolic capability generally requires the enrichment technique [28]. Three of seven samples Khairpur soil sample A (KSSA), Khairpur soil sample C (KSSC), and Khairpur soil sample D (KSSD) - displayed 
maximum growth absorbance at the final concentration (300 ppm) and based on maximum growth, absorbance samples (MSM broth) were selected for the isolation of B. parabrevis.

\section{Identification of the Oil-Based Paint Degrading Bacterial Strain}

The bacterial isolate NAP3 was grown and identified based on its colony morphology, physicochemical characteristics, and 16S rDNA sequence analysis. The bacterial strain NAP3 displayed specific colony morphology on MSM agar. It was circular, small pin point, smooth, convex, white, slow growing, moist, and with irregular margins. The results of morphological and biochemical tests preliminarily identified the isolate as $B$. parabrevis. The $16 \mathrm{~S}$ rDNA gene sequence of strain NAP3 showed 99\% similarity to Brevibacillus parabrevis M3 dbj[AB215101.1]; therefore, it was identified as $B$. parabrevis (Table 1 and Fig. 1). Usually, the bacteria Bacillus and Pseudomonas isolated genera are more active microorganisms having the potential to degrade many organic compounds, i.e., oil-based paint, pyrethroids, and organophosphorus pesticides [30-32]. The reports about the isolated microorganisms degrading oil-based paint from Bacillus genus are frequently found, but the isolated bacteria $B$. parabrevis is not previously isolated and described in bioremediation experiments. It appears to be a novel bacterial strain that participates in the degradation of oil-based paints. The accession number $\mathrm{gb}$ [KJ872854.1] was received from the NCBI GenBank against submitted nucleotide sequences. However, several studies have shown that Bacillus sp exhibited the highest prevalence on painted surfaces, paintings, and paints. This may be attributed to the survival strategies evolved by it [33].

\section{Biodegradation of Oil-Based Paint}

Another possible method for increasing the tolerance of cells to substrate inhibition is to supplement the growth medium with other conventional carbon sources (stimulation), such as yeast extract or glucose. It has also been noted that the presence of glucose enhanced the affinity of bacterial isolates for such aromatic hydrocarbons as phenol [34]. Therefore, biodegradation of oil-based paint (300 ppm) in MSM broth was carried out with and without a glucose source (additional carbon and energy source) for 14 days. Fig. 2 illustrates the growth and oil-based paint removal kinetics of the bacterial isolate $B$. parabreviss strain (NAP3) under shake flask conditions. Maximum growth absorbance was recorded on day 6 of incubation using a spectrophotometer (Jeenway-6300, Germany) at $600 \mathrm{~nm}$. It was observed that $B$. parabreviss attained maximum growth O.D $(600 \mathrm{~nm})$ of 1.23 and $85 \%$ removal ( $\lambda$ Max $285 \mathrm{~nm}$ ) of oil-based paint (residual oil-based paint conc. $48 \mathrm{ppm}$ ) during 14 days of incubation when the MSM was supplemented with glucose. The isolate $B$. parabrevis without glucose attained less biomass, having
Table 1 Morphological and Biochemical characteristics of the bacterial isolate (NAP3) degrading oil-based paint in aqueous media.

\begin{tabular}{|c|c|}
\hline Identification Test/Reaction & Test Result \\
\hline \multicolumn{2}{|l|}{ Morphology } \\
\hline Shape & Bacilli \\
\hline Gram's reaction & + \\
\hline Capsule staining & - \\
\hline Spore staining & + \\
\hline Flagella staining & + \\
\hline \multicolumn{2}{|c|}{ Sugar fermentation profile } \\
\hline Glucose & + \\
\hline Lactose & + \\
\hline Manitol & - \\
\hline Sucrose & + \\
\hline Galactose & - \\
\hline \multicolumn{2}{|c|}{ Biochemical reaction } \\
\hline Indole & - \\
\hline Methyl red & - \\
\hline Voges proskauer & - \\
\hline Citrate utilization & + \\
\hline Catalase & + \\
\hline Oxidase & + \\
\hline Nitrate reduction & + \\
\hline Urease test & - \\
\hline
\end{tabular}

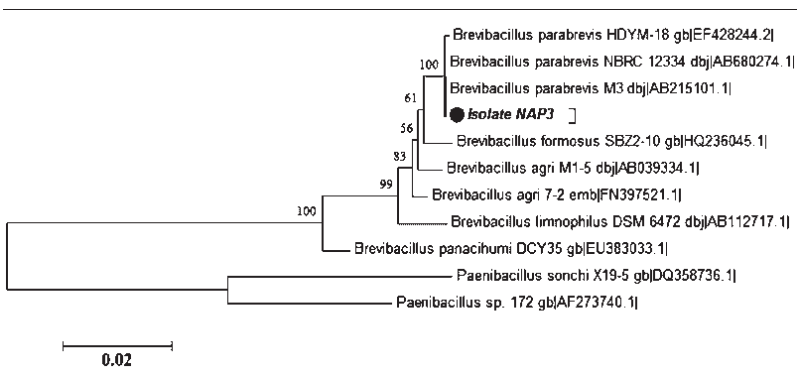

Fig. 1. Phylogenetic tree showing evolutionary relationship of isolate NAP3 with closely related taxa. The evolutionary history was inferred using the neighbor-joining method [41]. The optimal tree with the sum of branch length equaling 0.21775441 is shown. The percentage of replicate trees in which the associated taxa clustered together in the bootstrap test $(1,000$ replicates) are shown next to the branches [42]. The tree is drawn to scale, with branch lengths in the same units as those of the evolutionary distances used to infer the phylogenetic tree. The evolutionary distances were computed using the maximum composite likelihood method [22], and are in the units of the number of base substitutions per site. There were a total of 1,349 positions in the final dataset. Evolutionary analyses were conducted in MEGA6 [23]. 


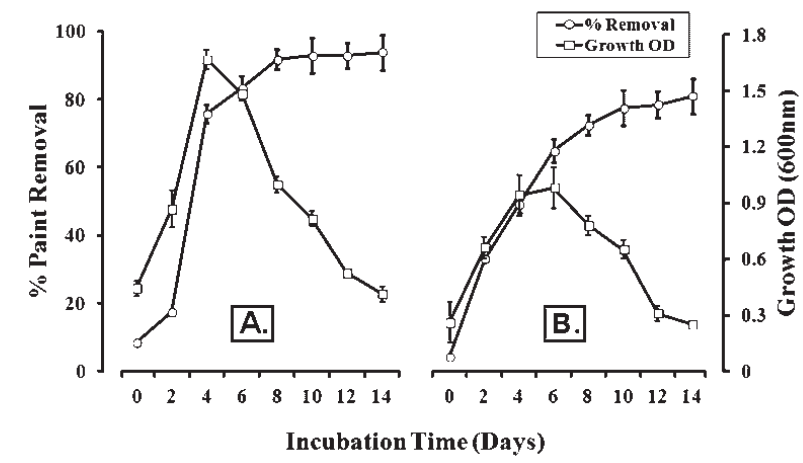

Fig. 2. Bacterial growth and percentage of oil-based paint removal by Brevibacillus parabrevis (NAP3). The growth at primary axis and percentage of oil-based paint removal was monitored in MSM supplemented with (A) and without glucose (B) in addition to oil-based paint (final conc. $300 \mathrm{ppm}$ ) for a period of 14 days.

growth O.D of $0.91(600 \mathrm{~nm})$, resulting in $73 \%$ oil-based paint removal ( $\lambda$ Max $285 \mathrm{~nm}$ ) and leaving behind residual oil-based paint concentration of $78 \mathrm{ppm}$ only. Besides the substrate tolerance, glucose supplementation reduces the acclimatization period and induces bacterial biomass.

\section{Fourier Transform Infra-Red-Attenuated Total Reflectance (FTIR-ATR) Spectrometry}

Infrared spectroscopy (infrared absorption frequencies) is a list of absorption peaks and frequencies, typically reported in wave number, for common types of molecular bonds and functional groups [35]. Therefore, the biodegradation of oil-based paint was also evident as illustrated by the FTIR spectra of cell-free supernatants before and after treatment. The FTIR spectra of the cellfree supernatants of $B$. parabrevis (NAP3) also confirmed noticeable changes in the oil-based paint relevant peaks at wave number frequency range of $800-600 \mathrm{~cm}^{-1}, 1,034$ to $1,299 \mathrm{~cm}^{-1}, 1,690$ to $1,725 \mathrm{~cm}^{-1}, 2,857$ to $3,000 \mathrm{~cm}^{-1}$, and 3,200 to $3,400 \mathrm{~cm}^{-1}$ in treated samples as compared to the samples before treatment corresponding to $\mathrm{C}-\mathrm{H}, \mathrm{C}-\mathrm{O}-\mathrm{N}$, $\mathrm{C}-\mathrm{O}-\mathrm{C}, \mathrm{CH}_{2}$ aliphatic stretch and terminal $\mathrm{CH}_{3}$ bonds, and N-H bonds, respectively (Fig. 3).

\section{Toxicity Assessment}

\section{Cytotoxic Effect}

The Bacillus sp. are found to improves the survival of genotobiotic brine shrimp (Artemia franciscana) larvae when challenged with Vibrio campbellii by enhancing the innate immune response and by decreasing the activity of brine shrimp-associated vibrios [36]. The brine shrimp toxicity analysis of the present study revealed that the oilbased paint before treatment displayed toxicity to the brine shrimp with glucose LD50 of $83 \mu \mathrm{l} / \mathrm{ml}$, while without glucose the level of LD50 was $94 \mu 1 \mathrm{ml}^{-1}$. B. parabrevis

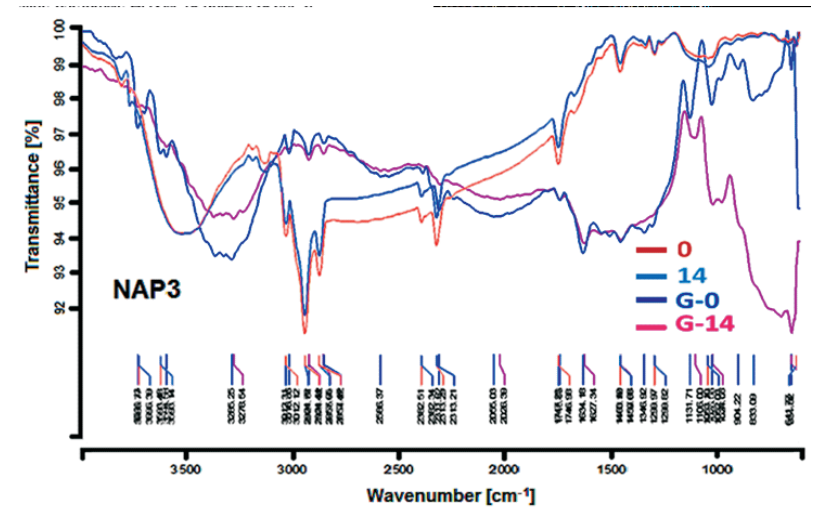

Fig. 3. FTIR-ATR spectra of cell-free culture supernatants (CFCS) of B. parabrevis strain (NAP3). The spectra were taken at days 0 and 14 (before and after treatment) for the percentage removal of oil-based paint residues in CFCS without glucose (0 and 14) and with glucose (G-0 and G-14).

with glucose after treatment displayed negligible toxicity against brine shrimp, indicating that the maximum utilization of oil-based paint with glucose might support the release of non-toxic metabolites, while without glucose the toxicity of oil-based paint decreased after treatment that might be due to incomplete utilization of oil-based paint without glucose. B. parabrevis has utilized the oilbased paint and removed the toxicity to generate less toxic metabolites and rendering it to be non-toxic against brine shrimp larvae in experimental conditions (Table 2).

\section{Phytotoxic Effect}

Phytotoxicity analysis was carried out before and after treatment of oil-based paint (300 ppm w/v) in MSM broth supplemented with and without glucose. The samples (CFCS) were tested for their phytotoxic activity against wild radish seeds at $500 \mu \mathrm{l}(0.5 \mathrm{ml})$ concentration. Table 2 illustrates the results of the percentage of inhibition of shoot length, root length inhibition percentage, mean period of final germination (MPFG), and root length corresponding to final germination percentage of the wild radish seeds under laboratory conditions. It was found that in both experimental conditions, i.e., with and without glucose supplementation, the isolate of the present study showed a reduction in percentage inhibition of shoot length and root length corresponding to a reduction in phytotoxicity of the oil-based paint by B. parabrevis. The reduced inhibition thus resulted in better \% final germination of the seeds, i.e., $98-100 \%$ germination in CFCS of MSM broth supplemented with and without glucose.

The percentage germination of wild radish seeds increased $80-97 \%$ with glucose after treatment of oilbased paint with the above-mentioned bacterial isolates at the same concentration of sample $(500 \mu \mathrm{l})$, while without glucose the maximum percentage of germination after treatment of oil-paint in MSM broth was attained when treated with the CFCS of B. parabrevis strain NAP3 (Table 2). Overall, the percentages of root and shoot length 
Table 2. Toxicity analysis (phytotoxic and cytotoxic effect) of the cell free culture supernatant of B. parabrevis strain (NAP3).

\begin{tabular}{|c|c|c|c|c|c|c|c|c|c|}
\hline \multirow{3}{*}{ Toxicity analysis } & \multicolumn{6}{|c|}{ Effect of treated Vs. untreated oil-based paints solution } & \multirow{3}{*}{$\mathrm{NC}$} & \multirow{3}{*}{$* \mathrm{PC}$} & \multirow{3}{*}{ **PC } \\
\hline & \multicolumn{3}{|c|}{ NAP3 (Without Glucose) } & \multicolumn{3}{|c|}{ NAP3 (With Glucose) } & & & \\
\hline & control & 0 day & 14 days & control & 0 day & 14 days & & & \\
\hline \multicolumn{10}{|c|}{ Phytotoxic effect (against wild raddish seeds) } \\
\hline $\mathrm{SLI} \%$ & $29.2 \pm 0.7$ & $28.9 \pm 0.6$ & $7.4 \pm 0.6$ & $28.7 \pm 1.2$ & $27.5 \pm 1.2$ & $4.5 \pm 0.2$ & 0 & $78.3 \pm 2.4$ & $92.0 \pm 3.6$ \\
\hline RLI\% & $17.7 \pm 0.7$ & $21.7 \pm 0.6$ & $3.9 \pm 0.6$ & $29.3 \pm 1.2$ & $26.17 \pm 1.2$ & $13.0 \pm 0.2$ & 0 & $89.2 \pm 2.4$ & $97.0 \pm 3.6$ \\
\hline $\mathrm{FG} \%$ & $100.0 \pm 4.0$ & $100 \pm 4.0$ & $100 \pm 4.0$ & $95.0 \pm 3.0$ & $100 \pm 4.0$ & $100 \pm 4.0$ & $100 \pm 1.0$ & $13.0 \pm 2.0$ & $2.0 \pm 0.5$ \\
\hline ISGP & 0 & 0 & 0 & $5.0 \pm 1.0$ & 0 & 0 & $0.0 \pm 0.04$ & $86.0 \pm 0.01$ & 100 \\
\hline MPFG & $2.7 \pm 0.03$ & $2.8 \pm 0.1$ & $2.7 \pm 0.0$ & $2.7 \pm 0.2$ & $2.5 \pm 0.4$ & $2.6 \pm 0.4$ & $1.5 \pm 0.05$ & $4.3 \pm 0.34$ & 0 \\
\hline RG & $6.7 \pm 0.1$ & $7.7 \pm 0.25$ & $7.2 \pm 0.3$ & $8.04 \pm 2.7$ & $8.7 \pm 2.1$ & $8.1 \pm 0.9$ & $16.2 \pm 1.5$ & $0.8 \pm 0.3$ & 0 \\
\hline GI & $0.95 \pm 0.05$ & $0.9 \pm 0.03$ & $0.95 \pm 0.01$ & $1.0 \pm 0.1$ & $1.0 \pm 0.2$ & $0.95 \pm 0.5$ & $1.02 \pm 0.2$ & $0.15 \pm 0.05$ & 0 \\
\hline \multicolumn{10}{|c|}{ Cytotoxic effect against Brine Shrimps larvae $(\mu \mathrm{l} / \mathrm{ml})$} \\
\hline $333.3(\mu \mathrm{l} / \mathrm{ml})$ & 96.5 & 94.5 & 18.5 & 97.5 & 95 & 12.5 & nd & $\mathrm{n} / \mathrm{a}$ & $\mathrm{n} / \mathrm{a}$ \\
\hline $166.6(\mu \mathrm{l} / \mathrm{ml})$ & 82.5 & 73.5 & 7.5 & 72.5 & 68.2 & 7.5 & nd & $\mathrm{n} / \mathrm{a}$ & $\mathrm{n} / \mathrm{a}$ \\
\hline $83.3(\mu \mathrm{l} / \mathrm{ml})$ & 45.8 & 44.2 & 0 & 52.5 & 50 & 0 & nd & $\mathrm{n} / \mathrm{a}$ & $\mathrm{n} / \mathrm{a}$ \\
\hline $\mathrm{LD}_{50}(\mu \mathrm{l} / \mathrm{ml})$ & 94.13 & 94.42 & $>400$ & 74.14 & 83.52 & $>400$ & nd & $\mathrm{n} / \mathrm{a}$ & $\mathrm{n} / \mathrm{a}$ \\
\hline
\end{tabular}

Note: SLI $\%$ = Shoot length inhibition percentage; RLI\% = Root length inhibition percentage; FG\% = Final germination percentage; ISGP = Inhibition in seedling germination percentage; $\mathrm{MPFG}=$ Mean period of final germination; $\mathrm{RG}=\mathrm{Rate}$ of germination; $\mathrm{GI}=$ germination index; Control (MSM containing oil-based paint at a conc. $300 \mathrm{ppm}, \mathrm{w} / \mathrm{v}$ ); $\mathrm{NC}=$ negative control (distilled water); $* \mathrm{PC}=$ first positive control (2,4-dichloroacetic acid, $500 \mu \mathrm{l}) ; * * \mathrm{PC}=$ second positive control (2,4-dichloroacetic acid, $1000 \mu \mathrm{l})$; $\mathrm{nd}=$ not determined; $\mathrm{n} / \mathrm{a}=$ not applicable; $\mathrm{LD}_{50}=$ lethal dose (minimum concentration) at which $50 \%$ of the brine shrimps died.

inhibition before treatment were significantly higher with or without glucose (as an additional carbon source), while after treatment of oil-based paint the percentages of root and shoot lengths were reduced. Roy et al. [37] confirmed the improvement of soil quality by testing on rice (Oryza sativa) and mung (Vigna radiata), and conducting an earthworm mortality bioassay in its microcosm study. They have concluded that the combined use of nutrient supplements along with crude oil (hydrocarbon)degrading bacteria could revive crude oil-contaminated soil effectively on a large scale.

\section{Antimicrobial Effect}

The analysis of toxicity was carried out in order to guarantee the safe and environmentally friendly removal

Table 3. Antimicrobial activity of cell free culture supernatant of B. parabrevis strain (NAP3).

\begin{tabular}{|c|c|c|c|c|c|c|c|c|}
\hline \multirow{3}{*}{$\begin{array}{c}\text { Test } \\
\text { Microorganism }\end{array}$} & \multicolumn{6}{|c|}{ Antimicrobial effect of treated Vs. untreated oil-based paints solution } & \multirow{3}{*}{$* \mathrm{PC}$} & \multirow{3}{*}{$* * \mathrm{PC}$} \\
\hline & \multicolumn{3}{|c|}{ NAP3 (Without Glucose) } & \multicolumn{3}{|c|}{ NAP3 (With Glucose) } & & \\
\hline & control & 0 day & 14 days & control & 0 day & 14 days & & \\
\hline \multicolumn{9}{|c|}{ Antibacterial activity (Zone of inhibtion in $\mathrm{mm} \pm$ Std. Dev.) } \\
\hline ML & $7.0 \pm 0.2$ & $7.5 \pm 0.0$ & 0 & $7.5 \pm 0.1$ & $7.0 \pm 0.2$ & 0 & $14.5 \pm 0.1$ & $\mathrm{n} / \mathrm{a}$ \\
\hline ST & $8.1 \pm 0.1$ & $7.4 \pm 0.2$ & 0 & $8.1 \pm 0.2$ & $7.4 \pm 0.1$ & 0 & $12.5 \pm 0.2$ & $\mathrm{n} / \mathrm{a}$ \\
\hline $\mathrm{PA}$ & $7.0 \pm 0.1$ & $7.5 \pm 0.1$ & 0 & $7.0 \pm 0.15$ & $7.5 \pm 0.1$ & 0 & $14.0 \pm 0.2$ & $\mathrm{n} / \mathrm{a}$ \\
\hline \multicolumn{9}{|c|}{ Antifungal activity (Zone of inhibtion in $\mathbf{m m}$ ) } \\
\hline AN & $7.8 \pm 0.2$ & $7.3 \pm 0.5$ & 0 & $7.8 \pm 0.2$ & $7.0 \pm 0.1$ & 0 & $\mathrm{n} / \mathrm{a}$ & $12.5 \pm 0.3$ \\
\hline AFM & $8.0 \pm 0.1$ & $7.0 \pm 0.2$ & 0 & $8.5 \pm 0.3$ & $8.0 \pm 0.2$ & 0 & $\mathrm{n} / \mathrm{a}$ & $18.0 \pm 1.2$ \\
\hline AFL & $10.0 \pm 0.3$ & $7.8 \pm 0.6$ & 0 & $9.3 \pm 1.1$ & $7.5 \pm 0.1$ & 0 & $\mathrm{n} / \mathrm{a}$ & $14.5 \pm 0.4$ \\
\hline
\end{tabular}

Note: $\mathrm{ML}=$ Micrococcus luteus; $\mathrm{ST}=$ Salmonella typhi $\mathrm{PA}=$ Pseudomonas aeruginosa $; \mathrm{AN}=$ Aspergillus niger $; \mathrm{AFM}=$ Aspergillus fumigatus; $\mathrm{AFL}=$ Aspergillus flavus; ${ }^{*} \mathrm{PC}=$ Positive control used in antibacterial assay (Cefotaxime, $200 \mu \mathrm{g}$ per well);

**PC $=$ Positive control used in antifungal assay (Clotrimazole, $200 \mu \mathrm{g}$ per well); $\mathrm{n} / \mathrm{a}=$ not applicable 
of biodegraded pollutant in the environment having less antimicrobial activity against normal soil flora. The toxicity analysis was performed against microbes (bacteria and fungi) before and after the treatment period of 14 days. Subsequently, the antibacterial activity of cell-free culture supernatant (B. parabrevis) was analyzed against the bacteria (M. luteus ATCC 10240, S. typhi ATCC 14028, $P$. aeruginosa ATCC 9027). Likely antifungal activity against fungal species (A. niger FCBP 0198, A. fumigatus FCBP 006, A. flavus FCBP 0064) was observed. We determined that toxicity to fungi was reduced completely when oil-based paint was treated for 14 days with and without glucose (Table 3). Alkotaini et al. [38] found that cell-free culture supernatant displayed a wide-range inhibitory spectrum in opposition together with Grampositive and -negative bacterial strains with the action of bactericidal against $E$. coli and $S$. aureus, while there was no activity against Staphylococcus marcescens and $B$. cereus. Similarly, the cell-free culture supernatant of $B$. parabrevis without glucose after treatment displayed complete toxicity removal against bacteria. On the other hand, treatment with glucose has displayed toxicity against pseudomonas only and complete removal against M. luteus and S. typhi (Table 3). Similarly, the CFCS of Paenibacillus alvei displayed its antimicrobial activity in opposition to E. coli, $S$. aureus $S$. marcescens, and B. cereus [38]. In contrast, Milillo et al. [39] reported the effective inhibiting growth of Listeria monocytogenes using cellfree culture supernatant from the lactic acid bacteria at very low MIC. Similarly, cell-free culture supernatants of $B$. subtilis subsp. subtilis strains also inhibited the growth of L. monocytogenes, M. luteus, S. aureus, and B. cereus, while cell-free culture supernatants of $B$. licheniformis strains only inhibited $M$. luteus [40]. In the present study, the antibacterial and antifungal activity with the cell-free culture supernatant of isolates (i.e., antimicrobial toxicity) before treatment could be attributed toward the toxicity of oil-based paint at $300 \mathrm{ppm}$ concentration or the presence of an abundant quantity of biocides in the oil-based paints used. However, low or no antimicrobial activity after the treatment of oil-based paint for 14 days in both experiments (i.e., with and without glucose), could be correlated with oil-based paint bioremediation and biodegradation.

\section{Conclusion}

We concluded that indigenous environments polluted with hazardous hydrocarbons like oil-based paint are choice sources for the isolation of potential oil-based paintdegrading bacteria. In the present study, B. parabrevis was successfully isolated and characterized as an oil-based paint-degrading strain that could tolerate elevated oilbased paint concentrations. The isolate possesses strong potential for oil-based paint degradation and can be used in the bioremediation of other hazardous hydrocarbonpolluted ecosystems. The isolated $B$. parabrevis strains utilized oil-based paints as the sole source of carbon and energy, and render them to be non-toxic with and without a nutritional supplement (additional carbon source). The isolated strain of B. parabrevis is novel in terms of its isolation source and bioremediation capability, with fewer harmful effects against other microbial communities, and might interact synergistically with the soil microbes to effectively degrade oil-based paint or related waste and might be helpful for future soil improvement applications.

\section{Acknowledgements}

We are thankful to Prof. Dr. Fariha Hassan, Chairperson of the Department of Microbiogy, Faculty of Biological Sciences, Quaid-i-Azam University in Islamabad for providing complete access to laboratory equipment and assigning research scholars for technical guidance in determining the percentage of oil-based paint removal from liquid media and FTIR analysis.

\section{References}

1. CHUN-LEI Z., LIANG L., CHUN-BO H.,DONG-SHENG W. Biodegradation of acetaldehyde by microorganisms in biological activated carbon filters. J. Bioremediat. Biodegrad. 4 (184), 2, 2013.

2. STREITBERGER H.-J. Von High zu Zero VOC. In Contribution at Congress GDCh, Division Paint Chemistry, Lüneburg/Germany, 2007.

3. SAFA M., ALEMZADEH I., VOSSOUGHI M. Biodegradability of oily wastewater using rotating biological contactor combined with an external membrane. J. Environ. Health Sci. Eng. 12 (1), 117, 2014.

4. CANCER I.A.F.R.O. Some organic solvents, resin monomers and related compounds, pigments and occupational exposures in paint manufacture and painting. IARC Monogr. Eval. Carcinog. Risks Hum. 47, 1990.

5. TESTA A., FESTA F., RANALDI R., GIACHELIA M., TIRINDELLI D., DE MARCO A., OWCZAREK M., GUIDOTTI M.,COZZI R. A multi-biomarker analysis of DNA damage in automobile painters. Environ. Mol. Mutagen. 46 (3), 182, 2005.

6. AZHDARPOOR A., MORTAZAVI B.,MOUSSAVI G. Oily wastewaters treatment using Pseudomonas $s p$. isolated from the compost fertilizer. J. Environ. Health Sci. Eng. 12 (1), 77, 2014.

7. AKCIL A. Destruction of cyanide in gold mill effluents: biological versus chemical treatments. Biotechnol. Adv. 21 (6), 501, 2003.

8. GURBUZ F., CIFTCI H., AKCIL A., KARAHAN A. G. Microbial detoxification of cyanide solutions: a new biotechnological approach using algae. Hydrometallurgy. 72 (1), 167, 2004.

9. GURBUZ F., CIFTCI H., AKCIL A. Biodegradation of cyanide containing effluents by Scenedesmus obliquus. J. Hazard. Mater. 162 (1), 74, 2009.

10. DASH R.R., GAUR A., BALOMAJUMDER C. Cyanide in industrial wastewaters and its removal: A review on biotreatment. J. Hazard. Mater. 163 (1), 1, 2009.

11. MIRIZADEH S., YAGHMAEI S., NEJAD Z.G. Biodegradation of cyanide by a new isolated strain under alkaline conditions and optimization by response surface methodology (RSM). J. Environ. Health Sci. Eng. 12, 85, 2014. 
12. KUMAR V., KUMAR V., BHALLA T.C. In vitro cyanide degradation by Serretia marcescens RL2b. Int. J. Environ. Sci. 3, 1985, 2013.

13. SHETE H.G., KAPDNIS B.P. Cyanide hydratase production using acclimatized strain of Streptomyces phaeoviridae and its characterization. Int. J. Bioassays. 2 (08), 1098, 2013.

14. GORBUSHINA A.A., HEYRMAN J., DORNIEDEN T., GONZALEZ-DELVALLE M., KRUMBEIN W.E., LAIZ L., PETERSEN K., SAIZ-JIMENEZ C., SWINGS J. Bacterial and fungal diversity and biodeterioration problems in mural painting environments of St. Martins church (GreeneKreiensen, Germany). Int. Biodeterior. Biodegr. 53 (1), 13, 2004.

15. RAVIKUMAR H.R., RAO S.S., KARIGAR C.S. Biodegradation of paints: a current status. Indian. J. Sci. Technol. 5 (1), 1977, 2012.

16. SUBATHRA M.K., IMMANUEL G., SURESH A.H. Isolation and identification of hydrocarbon-degrading bacteria from Ennore creek. Bioinformation. 9 (3), 150, 2013.

17. TURNER D.A., PICHTEL J., RODENAS Y., MCKILLIP J., GOODPASTER J.V. Microbial degradation of gasoline in soil: comparison by soil type. J. Bioremediat. Biodegrad. 5, 216, 2014.

18. WIESER M., SCHUMANN P., MARTIN K., ALTENBURGER P., BURGHARDT J., LUBITZ W., BUSSE H.-J. Agrococcus citreus sp. nov., isolated from a medieval wall painting of the chapel of Castle Herberstein (Austria). Int. J. Syst. Evol. Microbiol. 49 (3), 1165, 1999.

19. OMAR O.C., KIRSTEEN O.P., ONYANGO DAVID M., ANTHONY S. Molecular clustering of microbial flora and Bacterial degradation of textile dyes by isolates from contaminated soils. Biotechnology. 54, 12452, 2013.

20. YONETANI R., IKATSU H., MIYAKE-NAKAYAMA C., FUJIWARA E., MAEHARA Y., MIYOSHI S.-I., MATSUOKA H., SHINODA S. Isolation and characterization of a 1, 3-dichloro-2-propanol-degrading bacterium. J. Health Sci. 50 (6), 605, 2004.

21. TAMURA K., NEI M. Estimation of the number of nucleotide substitutions in the control region of mitochondrial DNA in humans and chimpanzees. Mol. Biol. Evol. 10 (3), $512,1993$.

22. TAMURA K., NEI M., KUMAR S. Prospects for inferring very large phylogenies by using the neighbor-joining method. Proc. Natl. Acad. Sci. U.S.A. 101 (30), 11030, 2004.

23. TAMURA K., STECHER G., PETERSON D., FILIPSKI A., KUMAR S. MEGA6: molecular evolutionary genetics analysis version 6.0. Mol. Biol. Evol. 30 (12), 2725, 2013.

24. JAMIL M., UL HAQ I., MIRZA B., QAYYUM M. Isolation of antibacterial compounds from Quercus dilatata L. through bioassay guided fractionation. Ann. Clin. Microbiol. Antimicrob. 11 (1), 11, 2012.

25. SAXENA A., SINGH D.V., JOSHI N.L. Autotoxic effects of pearl millet aqueous extracts on seed germination and seedling growth. J. Arid Environ. 33 (2), 255, 1996.

26. ULLAH N., HAQ I.U., MIRZA B. Phytotoxicity evaluation and phytochemical analysis of three medicinally important plants from Pakistan. Toxicol. Ind. Health. 31 (5), 389, 2015.

27. BANERJEE A., GHOSHAL A.K. Isolation and characterization of hyper phenol tolerant Bacillus $s p$. from oil refinery and exploration sites. J. Hazard. Mater. 176 (1), 85,2010

28. SOUDI M.R., KOLAHCHI N. Bioremediation potential of a phenol degrading bacterium, Rhodococcus erythropolis SKO-1. Prog. J. Biol. Sci. 1, (1), 31, 2011.
29. MARCHESI J.R.,WEIGHTMAN A.J. Comparing the dehalogenase gene pool in cultivated $\alpha$-halocarboxylic aciddegrading bacteria with the environmental metagene pool. Appl. Environ. Microbiol. 69 (8), 4375, 2003.

30. ANWAR S., LIAQUAT F., KHAN Q.M., KHALID Z. M., IQBAL S. Biodegradation of chlorpyrifos and its hydrolysis product 3, 5, 6-trichloro-2-pyridinol by Bacillus pumilus strain C2A1. J. Hazard. Mater. 168 (1), 400, 2009.

31. MALONEY S.E., MAULE A., SMITH A.R.W. Transformation of synthetic pyrethroid insecticides by a thermophilic Bacillus sp. Arch. Microbiol. 158 (4), 282, 1992.

32. ZHANG C., WANG S., YAN Y. Isomerization and biodegradation of beta-cypermethrin by Pseudomonas aeruginosa $\mathrm{CH} 7$ with biosurfactant production. Bioresour. Technol. 102 (14), 7139, 2011.

33. ODOKUMA L.O., BEREBON D.P., OGBONNA C.B. Potential biodeteriogens of indoor and outdoor surfaces (coated with gloss, emulsion and textcoat paints). IOSR J. Pharm. Biol. Sci. 7 (1), 12, 2013.

34. LOH K.-C., TAN C.-P. Effect of additional carbon sources on biodegradation of phenol. Bulletin of environmental contamination and toxicology. 64 (6), 756, 2000.

35. SEGNEANU A.E., GOZESCU I., DABICIA., SFIRLOAGA P., SZABADAI Z. Organic Compounds FT-IR Spectroscopy. In Macro To Nano Spectroscopy, J. UDDIN (Ed.), InTech, 145, 2012.

36. NIU Y., DEFOIRDT T., BARUAH K., VAN DE WIELE T., DONG S.,BOSSIER P. Bacillus sp. LT3 improves the survival of gnotobiotic brine shrimp (Artemia franciscana) larvae challenged with Vibrio campbellii by enhancing the innate immune response and by decreasing the activity of shrimp-associated vibrios. Vet. Microbiol. 173 (3), 279, 2014.

37. ROY A.S., BARUAH R., BORAH M., SINGH A.K., BORUAH H.P.D., SAIKIA N., DEKA M., DUTTA N., BORA T.C. Bioremediation potential of native hydrocarbon degrading bacterial strains in crude oil contaminated soil under microcosm study. Int. Biodeterior. Biodegr. 94, 79, 2014.

38. ALKOTAINI B., ANUAR N., KADHUM A.A.H., SANI A.A.A. Detection of secreted antimicrobial peptides isolated from cell-free culture supernatant of Paenibacillus alvei AN5. J. Ind. Microbiol. Biotechnol. 40 (6), 571, 2013.

39. MILILLO S.R., STORY R.S., PAK D., O'BRYAN C.A., CRANDALL P.G., RICKE S.C. Antimicrobial properties of three lactic acid bacterial cultures and their cell free supernatants against Listeria monocytogenes. J. Environ. Sci. Health B. 48 (1), 63, 2013.

40. COMPAORÉ C.S., NIELSEN D.S., OUOBA L.I., BERNER T.S., NIELSEN K.F., SAWADOGO-LINGANI H., DIAWARA B., OUÉDRAOGO G.A., JAKOBSEN M., THORSEN L. Co-production of surfactin and a novel bacteriocin by Bacillus subtilis subsp. subtilis $\mathrm{H} 4$ isolated from Bikalga, an African alkaline Hibiscus sabdariffa seed fermented condiment. Int. J. Food Microbiol. 162 (3), 297, 2013.

41. SAITOU N., NEI M. The neighbor-joining method: a new method for reconstructing phylogenetic trees. Mol. Biol. Evol. 4 (4), 406, 1987

42. FELSENSTEIN J. Confidence limits on phylogenies: an approach using the bootstrap. Evolution. 783, 1985. 
